\title{
HISTÓRIAS - Um pretexto para a escrita
}

\author{
Eliete Paes Landim Azevedo ${ }^{1}$ \\ Orientador Marco Aurélio Borges ${ }^{2}$
}

\section{MESTRADO EM CIÊNCIAS DA EDUCAÇÃO}

\section{RESUMO}

A inquietação sobre a educação no Brasil perpassa por um desejo de práticas democráticas e transformadoras devido aos altos índices de analfabetismo e falta de oportunidades. Percebemos a necessidade de trabalhar com algo que dê sentido para voltar à escuta e produção de textos orais e escritos de fato com propósitos. Nesta proposta de investigação junta-se um grupo de alunos para a realização de estudos na escola, em referência a realidade das crianças e sua formação humana, as experiências dos educandos e do professor com a leitura e escrita através da Contação de histórias e a produção de textos, para que se coloquem como locutores em potencial. Um estudo que colabore com a atribuição de sentido e consciência crítica ao longo do processo de ensino-aprendizagem de professor e alunos, com estratégias de ensino e atividades didáticas elaboradas e vivenciadas pelo grupo, com intencionalidade para propor produções de textos orais e escritos aos alunos em variados gêneros textuais, de nossas vivências de práticas pedagógicas que considerem o discurso do aluno como razão de ser da produção textual. A criatividade nas produções de texto resulta em apresentações bem elaboradas de teatro em fantoches, palco apresentação, direção ensaiando com outra turma, além do aprimoramento da escrita e leitura, nosso principal objetivo.

Palavras-chave: Contação de histórias. Alfabetização. Escrita. Produção de texto. Intervenção. Séries Iniciais.

\footnotetext{
${ }^{1}$ Atualmente é Professora efetiva de Séries Iniciais da Escola Estadual General Tibúrcio - SEDU - ES. Professora efetiva na Educação Infantil no CMEI Darcy Rodrigues Cardoso - PMC - ES. Tem experiência na área de Educação: Experiência em Formação Continuada na Educação de Jovens e Adultos e Professores de séries iniciais como Formadora; Contadora de histórias e Montagem Teatral; e Coordenadora de Turno. Especialização em Gestão Integradora e Arte-Educação. Mestranda em Educação.)

${ }^{2}$ Graduado em Ciências Sociais, especialista em Psicopedagogia e Mestre em Cognição e Linguagem pela Universidade do Norte Fluminense Darcy Ribeiro - UENF Doutor em Ciências Humanas/Sociologia pelo Programa de Pós-Graduação em Sociologia e Antropologia da Universidade Federal do Rio de Janeiro (bolsista Cnpq).Pesquisador associado ao Núcleo de Pesquisas em Cidadania, Conflito e Violência Urbana, no âmbito da Universidade Federal do Rio de Janeiro. Período de bolsa de pós doutorado na Universidade Estadual do Norte Fluminense Darcy Ribeiro.
} 


\section{INTRODUÇÃO}

A inquietação sobre a educação no Brasil perpassa por um desejo de práticas democráticas e transformadoras. No Espírito Santo 36,7\% dos estudantes estão no Nível 3 de leitura. Conforme microdados do Saeb/ANA 2016/Inep.

"O Nível 3, além da compreensão geral de textos mais longos e complexos, concentra habilidades que requerem relacionar várias informações contidas no texto e um maior nível inferencial, tais como inferir sentido de expressão ou palavras e assunto em textos verbais e não verbais".

Estamos no SAEB com $66,4 \%$ dos estudantes no Nível 4 de leitura.

No Nível 4 os estudantes provavelmente escrevem as palavras apresentadas corretamente, independentemente de sua complexidade, e atendem à proposta de construir uma narrativa, embora ainda possam incorrer em desvios que comprometem parcialmente o sentido desta. É preciso atenção ao fato de que $25,1 \%$ dos estudantes estão concentrados nos níveis 1,2 e 3 , que compreendem desde aqueles que ainda não escrevem palavras ou as escrevem de forma incompreensível até os estudantes que produzem textos com desvios que comprometem sua compreensão (INEP, 2016).

É necessário investigar caminhos para um aprimoramento didático. É preciso que se considere o conhecimento trazido pelo educando e que se possibilite a sua ampliação garantindo o direito de aprender. Paulo Freire afirma: "a alfabetização é feita de dentro para fora pelo próprio analfabeto e apenas ajustado pelo educador" (FREIRE, 1975, p. 72).

A formação inicial do magistério não garante a abrangência do ensinar e do aprender, como ressalta Nóvoa (2001, p.20) "Embora tenha havido uma verdadeira revolução nesse campo nos últimos vinte anos, a formação ainda deixa muito a desejar". Segundo o autor as instituições ficam fechadas em si mesmas, ora por um academicismo excessivo ora por um empirismo tradicional. Para minimizar as lacunas, a continuidade da formação faz-se necessária. Dessa forma busca-se nas teorias e nas próprias pesquisas contribuições para a prática pedagógica que tornem possível inovar as próprias estratégias de ensino ou mesmo utilizar as experiências já adquiridas com um novo olhar. 
O Ministério da Educação vigorou em 5 de julho de 2012 a Portaria nำ - 867, de 4 de julho de 2012 onde foi instituído o PNAIC - Pacto Nacional pela Alfabetização na Idade Certa e suas ações do Pacto e definiu suas diretrizes gerais. Onde seu principal objetivo era garantir a todos os alunos do $1^{\circ}$ ao $3^{\circ}$ ser alfabetizados. Com a formação dos professores com Orientadores de estudos e monitoramento da prática pedagógica nas escolas.

§ 3으 As ações de formação serão conduzidas e monitoradas no âmbito dos estados, do Distrito Federal e dos municípios, reforçando a responsabilização das redes de ensino pelo desenvolvimento das atividades e resultados do Programa (BRASIL, 2012).

Fazendo parte na assessoria aos professores e pedagogos e na formação do Pacto Nacional pela Alfabetização na Idade Certa - PNAIC, identificamos ainda a predominância de ação pedagógica centrada na mecânica e na memória, pouco direcionada para a elaboração de sentidos e com pouco espaço para a vivência da criança no seu processo de construção do conhecimento e dificuldades em propor trabalhos com produção de textos orais e escritos na sala de aula, bem como elaborar proposições, diagnósticos e intervenções, ficando esse trabalho reduzido a etiquetas em desenhos, frases e descrições a partir de gravuras, desvinculado dos tipos de textos circulados em nossa sociedade, levando a produção do educando a se resumir em cumprir a atividade escolar, embasados em relatórios de visitas.

De volta à sala de aula é percebido a necessidade de trabalhar com algo que dê sentido para à escuta e produção de textos orais e escritos de fato com propósitos. Esse é o nosso foco: a produção de texto no processo de leitura e escrita.

Nessa proposta de investigação junta-se um grupo de alunos para a realização de estudos na escola, em referência a realidade das crianças e sua formação humana, as experiências dos educandos e do professor com a leitura e escrita através da Contação de histórias e a produção de texto, para que se coloquem como locutores em potencial. Um estudo que colabore com a atribuição de sentido e consciência crítica ao longo do processo de ensino-aprendizagem de professor e alunos, com estratégias de ensino e atividades didáticas elaboradas e vivenciadas pelo grupo, com intencionalidade para propor produções de textos orais e escritos aos alunos em variados gêneros textuais, de nossas vivências de práticas pedagógicas que considerem o discurso do aluno como razão de ser da produção textual. De acordo 
com Geraldi (2003), o texto deve ser o ponto de partida e ponto de chegada para o ensino da língua por que é nele que a língua se revela como forma (aspectos linguísticos) e como discurso.

Dia-a-dia nossa realidade vai se mostrando reflexiva para fazer o aluno perceber a necessidade de ler e escrever, de criar sua própria história. Sustentados nos estudos de Gontijo e Schwartz (2008) que consideram a leitura e a escrita como uma prática sociocultural, busca-se compreender a necessidade da escrita em nossa sociedade, pois hoje o domínio da leitura e escrita são necessidades de sobrevivência. Incomodanos perceber que muitas crianças terminam o ciclo de alfabetização ( $1^{\circ}$ ao $3^{\circ}$ ano) sem saber ler e escrever. Faz-se necessário que essa verdade seja superada por nossos alunos.

Tendo como ponto de partida a contação de histórias, refletindo sobre o fascínio que o trabalho com ela desperta, levando em consideração que é importante seguir uma direção histórico-cultural de maneira consciente e sistemática, respeitando o desenvolvimento intelectual e interesses pessoais das crianças através de estratégias pedagógicas que estimulam o processo ensino e aprendizagem, que elaboramos este trabalho. Estimulando-as a ouvir e interpretar a seu modo, recebendo informações sobre o autor das histórias, arriscar-se a dramatizar percebendo que outros podem ser convidados a ver sua atuação, sentir necessidade de elaborar e produzir um convite, elaborar falas para seus personagens, criar outros finais, ler determinados tipos de expressões, conviver com tecnologias existentes que produzem imagens e textos, perceberemos como as crianças poderão se interessar de maneira prazerosa pela apropriação do ler e escrever, mesmo aquelas com muita dificuldade.

O uso de histórias e dramatização favorece a aquisição da leitura e escrita e podem ser usadas no processo de alfabetização. A contação de histórias é utilizada desde o tempo mais remoto de maneira inicialmente oral e em nossos dias, também de maneira escrita. O teatro também é antigo surgiu a partir do cotidiano e suas necessidades como se expressar na sua forma mais primitiva.

Assistindo a uma Série de TV chamada "A Incrível Jessica James", onde uma dramaturga que é a personagem principal, incentiva crianças a escrever textos para o teatro, veio a vontade e pesquisa para fazer algo parecido com as nossas, para a 
produção escrita. E assim, contando histórias e as fazendo preparar para representálas, surge o projeto de pesquisa e intervenção, com o propósito de ver nascer conhecimento e produção para adequação em nossa prática neste tempo e em trabalhos posteriores, individualmente e com nossos colegas em formação.

\title{
2. METODOLOGIA
}

Nossa opção metodológica para a pesquisa de estudo abordada é a "pesquisa qualitativa" que segundo LUDKE (1986, p.44) tem como características:

\begin{abstract}
A pesquisa qualitativa tem o ambiente natural como sua fonte direta de dados e o pesquisador como seu principal instrumento; os dados coletados são predominantemente descritivos; a preocupação com o processo é muito maior do que com o produto; o significado que as pessoas dão às coisas e à sua vida são focos de atenção especial pelo pesquisador; a análise dos dados tende a seguir um processo indutivo.
\end{abstract}

Nossos sujeitos nesta pesquisa são os educandos de uma escola pública, que oferece o ciclo de alfabetização. Baseada nas características da pesquisa qualitativa e na parceria com os educandos, está sendo oferecida uma ação didática, visando contribuir nos planejamentos e nas ações pedagógicas de sala de aula, considerando a necessidade de implementar práticas reais de produção de textos contendo ações como reflexão sobre a concepção no trabalho de alfabetização, organização de elementos que caracterizam a produção textual em nossa sociedade, verificando a presença ou não, em práticas com os alunos em sala de aula; análise da importância da abordagem da leitura e produção de textos para conhecimentos sobre o nosso sistema de escrita; compreensão de concepções de alfabetização na perspectiva da discursividade; sistematização de aportes teóricos que possam orientar as ações de mediação para intervir na produção de texto do aluno tentando não desprestigiá-lo ou desanimá-lo na busca da aquisição da escrita ortográfica; registro de necessidades de aprendizagem em instrumento próprio para ser socializado entre os pares ou pedagoga a partir das produções textuais realizadas pelas crianças; criação de estratégias e dinâmicas de propostas para produção de textos orais e escritos; revisão de literatura para parâmetros teóricos; autoavaliação da prática; relatos exitosos ou não, cenas de sala de aula e apresentações com o devido consentimento dos pais para aprofundamento de reflexão e pesquisa. 
A partir da análise do próprio trabalho e dos envolvidos em cada encontro ou atividades, planejamos e replanejamos os encontros tendo como perspectiva e referência as necessidades dos envolvidos, de cada um de nós.

As ações estão sendo registradas e gravadas para estudos em diferentes momentos durante a pesquisa, o que nos dão variados momentos de reflexão-ação-reflexão para a produção de conhecimento que nos auxiliam a compartilhar respostas. Algumas delas:

- Audição de contos e histórias

- Texto coletivo, individual e em duplas com roteiros para teatro. Finalizando de maneira apropriada conforme gosto individual, dupla e votação do grupo.

- Correção de possíveis erros ortográficos e gramaticais

- Uso do dicionário e criação de glossário e verbetes.

- Ensaio dos roteiros na prática

- Confecção de convites e banners para apresentações.

- Apresentações para os convidados

As reflexões realizadas bem como os dados coletados estão sendo analisadas à luz do referencial teórico deste projeto, para a construção de práticas pedagógicas reflexivas no trabalho cotidiano.

\section{REFERENCIAL TEÓRICO}

GONTIJO afirma que a prática de produção de textos orais convive com a prática de textos escritos para que os estudantes assumam-se como sujeitos e sejam motivados a falar e escrever sobre suas experiências, tenham interlocutores para seus textos, e considerando o que têm a dizer aos seus destinatários, escolher as melhores estratégias para compor seus textos. A autora ressalta também que, por meio dos textos, com objetivos e destinatários, podemos ajudar as crianças a refletirem sobre a língua e fazer uso dos conhecimentos sobre o sistema de escrita que estão sendo apreendidos. (2007). 
Geraldi (2003, p.160), traça um quadro de condições necessárias à produção de um texto:
a) se tenha o que dizer;
b) se tenha uma razão para dizer o que se tem a dizer;
c) se tenha para quem dizer o que se tem a dizer;
d) o locutor se constitua como tal, enquanto sujeito que diz o que diz para quem diz;
e) se escolham as estratégias para realizar (a), (b), (c) e (d).

Através desta pesquisa participante encontramos subsídios à construção de atividades de ensino para a produção de textos orais e escritos por meio de estudo/prática entre um grupo de alunos, tendo estes educandos interlocutores reais, definindo estratégias do discurso com conteúdo adequado a esses destinatários.

\subsection{CONTAÇÃO DE HISTÓRIAS}

Fomos encontrando bibliograficamente elementos didáticos para serem utilizados para uma boa contação de histórias, para criação de textos em variados gêneros textuais, como em convites, cartazes e banners para serem lidos de maneira real e atraente. As crianças vão se encantando em ouvir histórias do mesmo modo como as de antigamente como relata Glória Kirinus no prefácio, na orelha do livro Contar e Encantar de Cléo Busatto, 2017:

\footnotetext{
Cumulativa voz, de milenar encanto, que nasce do ventre da roda, atravessa auditórios, oficinas, cursos de comovidos ouvintes e hoje acompanha a nova espiral do próprio prazer, virando letra viva, inquieta e bem articulada. Cléo Busatto convida outras vozes para pensar com ela o mistério das metáforas que surpreendem o próprio mito e, assim, levanta significados densos nos enigmas que perseguem a origem de nossa humanidade.
}

Em nosso tempo a história é escrita e reescrita caminhando por vários lugares desde um lar especificamente para uma ou várias pessoas, uma sala de aula, ou um grupo comunitário. Até mesmo contada oralmente.

\subsection{O TEATRO}

O desenho primitivo deu a forma de expressão criadora e foi pelo teatro que com certeza expandiu essa ação. Depois de variados espetáculos de onde nem se pode imaginar, veio o sucesso do teatro Grego que através de Tragédias e Comédias 
encantou o mundo. Com o advento da escrita o espetáculo se consolidou a ser transcrito e imitado por outras pessoas de onde não precisavam ser autores exatamente.

$\mathrm{O}$ ator e todos os pares do teatro necessitam de leitura para encantamento e memorização na execução do projeto e atuação, assim como nossos alunos terão ao tentar entender e dramatizar também no pretexto para a leitura e escrita.

O texto dramático, ou teatral são feitos com o intuito de serem encenados ou dramatizados e tem característica própria como diálogos e monólogos, cenas e rubricas (linguagem de voz e gestual e sonoplastia). Estudadas também em nosso livro didático (obra coletiva) Buriti Português Mais, 2017.

Os principais autores do gênero dramático na Grécia antiga foram: Sófocles (496-406 a.C.), Eurípedes (480-406 a.C.) e Ésquilo (524-456 a.C.), conforme DIANA na revista online Toda Matéria.

\subsection{A LEITURA E A ESCRITA}

A edição online 109 do Portal do Professor oferece sugestões de livros aos professores e educadores interessados em estimular o hábito de leitura aos alunos da educação básica. Uma delas é o livro de Cláudia Stocker chamado Um Incentivo à Leitura - Era Uma Vez, 2014 onde expõe a divulgação da editora Brasil com um texto que relata uma verdade que merece ser lida:

\footnotetext{
É na infância que se adquire o hábito de ler; é na criança que estão todas as potencialidades e disponibilidades para o prazer da leitura e é evidente também, que se torna necessário abrir para elas, as janelas desse mundo maravilhoso. Ler e contar história são formas de desenvolver o gosto pela fantasia, incentivando nos pequeninos aspectos que dizem respeito ao seu potencial criativo. Ao ouvir histórias narradas por contadores que transformam palavras e gestos em pura magia e encanto, é que queremos mostrar ao leitor, como o despertar para a leitura pode ser iniciado nas primeiras etapas da vida através da tradição oral. (acesso em julho de 2019)
}

$\mathrm{Na}$ abordagem histórico-cultural o ensino da língua supera as unidades menores, na medida em que só o texto permite compreender como a língua se realiza enquanto forma e discurso.

A alfabetização não envolve apenas aprender sílabas e palavras ou a passagem do discurso oral para discurso escrito e vice-versa, mas é também um processo de 
produção de sentidos por meio do trabalho de leitura e da escrita. Então, ler e escrever são atividades por meio das quais as crianças podem expor para os outros e para si mesma o que pensam, sentem, desejam, gostam, concordam, discordam etc. Nesse sentido, a interação com o outro, por meio da leitura e da escrita é um processo dialógico desde o início. (GONTIJO, 2008). É a escrita como discurso que fundamenta a teoria histórico-cultural em que ensinar a língua é preconizar a produção de textos na medida em que só ele permite compreender a língua como emergente das interações sociais.

Trabalhando neste aspecto de textos é que demonstramos nosso entendimento do que de fato a alfabetização é baseada na concepção discursiva da leitura que segundo Gontijo é:

[...] como uma prática sociocultural em que se desenvolve a formação da consciência crítica, as capacidades de produção de textos orais e escritos, a leitura, os conhecimentos sobre o sistema de escrita da língua portuguesa, incluindo a compreensão das relações entre sons e letras e letras e sons (GONTIJO, 2008 p.15)

\subsection{PRODUÇÃO DA MUDANÇA}

Para Steban e Zaccur não faltam pesquisas de denúncia e anúncio, não faltam intervenções realizadas, não é vão todo o esforço despendido. A professora da escola básica não pode ser apenas consumidora passiva do conhecimento produzido pelos pesquisadores acadêmicos. Cabe também a ela parceria na produção da mudança que queremos ver no interior da escola. Ao aluno e à professora seja garantida a condição de produtores do conhecimento, pois não há como pensar a mudança sem a participação dos que vão construí-la no cotidiano da escola. Precisamos dar ao aprofundamento teórico o sentido de buscas de respostas, que se transformam em novas perguntas caminhando para desestruturar o senso comum, surgindo assim uma professora-pesquisadora que discute sobre o processo de ensino-aprendizagem no espaço de aprendizagem, vendo mais profundamente suas questões. (ZACCUR, 2002).

Uma coletânea de estratégias de ensino poderá surgir a partir das sequências didáticas elaboradas e vivenciadas com os educandos, com intencionalidade para propor produções de textos orais e escritos em sala de aula, fornecendo subsídios até 
a outros professores para implementação e vivências de práticas pedagógicas que considerem o discurso do aluno como razão de ser da produção textual.

O professor tem um "saber" dentro de si que é refletido em sua prática, mas precisa manter-se atualizado sobre as novas metodologias de ensino e desenvolver práticas pedagógicas mais eficientes, práticas essas que são alguns dos principais desafios da profissão de educador (NÓVOA, 2001). Dessa forma, precisamos compreender que o trabalho com produção de textos orais e escritos pode ser modificado, melhorado, reconstruído ou abandonado, tendo o seu cotidiano como referência. Precisamos provocar reflexão sobre a língua e fazer uso dos conhecimentos sobre o sistema de escrita por meio da produção textual do aluno. Precisamos criar estratégias para incentivar a produção de texto do aluno com situações próximas do real para que assim, ocorram as condições de produção, sem as quais os textos produzidos na escola estarão sempre condenados ao artificialismo.

\section{CONSIDERAÇÕES FINAIS}

Para Minayo (2010) a pesquisa é a atividade básica das Ciências Sociais que lida com seres humanos que por qualquer motivo tem algo em comum com o investigador, tornando-os solidariamente comprometidos, na sua indagação e construção da realidade. Como lembra Lévi-Strauss (in MINAYO, 2010). "Numa ciência, onde o observador é da mesma natureza que o objeto e o observador é ele próprio, uma parte da sua observação" (p.13). A pesquisa deve ter "método, instrumentos e a criatividade do pesquisador: experiência, capacidade pessoal e sensibilidade." (idem P.26).

A necessidade de saber mais e fazer melhor, é que faz uma busca atenta para compreender o que está sendo vivenciado, construir novas formas de entender a realidade e procurar algo que faça dos dilemas desafios que possam ser enfrentados.

A cada ação percorrida, vivenciada, sentimos a alegria de estar focado em um trabalho que demonstra contato coerente com a realidade. Escrita de fato a um interlocutor que aprecia a escrita com a necessidade de criar para este, um texto que vai lhe alcançar de verdade, pela necessidade que tem desta escrita. Como um convite ou cartaz em 
que o convidado precisa dele de fato, para poder estar lá participando e prestigiando o locutor.

A criatividade nas produções de texto resulta em apresentações bem elaboradas de teatro em fantoches, palco apresentação, direção ensaiando com outra turma, além do aprimoramento da escrita e leitura, nosso principal objetivo.

Essas são algumas das nossas inquietações e desejo de aprofundarmos nossos conhecimentos para contribuir com a meta de todos aqueles comprometidos com o fortalecimento de uma sociedade democrática, justa e solidária.

\section{REFERÊNCIAS}

A incrível Jéssica James. Acesso em junho, 2017.

(https://www.netflix.com/watch/80171022?trackld=13752289\&tctx=0\%2C1\%2Cad02 a83859e51c7656a6a937c8ccc9fe234a9423\%3A196eaa8c393a46f5bb01d45f1b4cf0f 3026121af\%2C\%2C)

BRASIL. Ministério da Educação. Secretaria da Educação Básica. Formação de Professores no Pacto Nacional pela Alfabetização na Idade Certa. Brasília: MEC/SEB, 2012. Acesso em julho de 2019.

. Portaria № 867, de 4 de julho de 2012. Institui o Pacto Nacional pela Alfabetização na Idade Certa e as ações do Pacto e define suas diretrizes gerais. Diário Oficial da União, № 129, quinta-feira, 5 de julho de 2012, p. 22-23.

BURITI MAIS: Português. Obra coletiva concebida e produzida pela Editora Moderna: editora responsável Mariza Martins Sanchez. São Paulo: Moderna, 2017.

BUSATTO, Cléo. Contar e encantar - Pequenos segredos da narrativa. Petrópolis, RJ: Vozes, 2012.

DAEB, Diretoria de Avaliação da Educação Básica, Relatório SAEB/ANA Panorama do Brasil e dos Estados. Acesso em julho de 2019.

file://D:/Documents/2020/RELATÓRIO\%20SAEBANA\%202016\%20PANORAMA\%2 0DO\%20BRASIL\%20E\%20DOS\%20ESTADOS.pdf

ESTEBAN, Maria Tereza e BACCUR, Edwiges (orgs.), Professora Pesquisadora uma práxis em construção. Rio de Janeiro: DP\&A, 2002.

FREIRE, Paulo. Pedagogia da esperança: um reencontro com a pedagogia do oprimido. Rio de janeiro: Paz e Terra, 2006. 
GERALDI, João Wanderley. A Leitura na Sala de Aula As Muitas Faces de Um Leitor http://www.crmariocovas.sp.gov.br/pdf/ideias 05 p079-084 c.pdf

Portos de Passagem. 4. ed. São Paulo: Martins Fontes, 2003.

GONTIJO, Cláudia Maria Mendes. Alfabetização: a criança e a linguagem escrita. Campinas: Autores associados, 2007.

GONTIJO, Cláudia Maria Mendes; SCHWARTZ, Cleonara Maria. Alfabetização: teoria e prática. Curitiba, PR: Sol, 2008.

INEP. Censo Escolar da Educação Básica. Notas estatísticas, acesso em maio,2017

http://download.inep.gov.br/educacao basica/censo escolar/notas estatisticas/2017/n otas estatisticas censo escolar da educacao basica 2016.pdf)

MINAYO, Maria Cecília de Souza (org.); DESLANDES, Suely Ferreira; GOMES, Romeu. Pesquisa Social: Teoria, método e criatividade. Petrópolis: 2010

NÓVOA, Antonio. Professor se forma na escola. Revista Escola, 2001. Disponível em <http://revistaescola.abril.com.br/formacao/formacao-continuada/professor-se-formaescola-423256.shtml>. Acesso em outubro, 2018.

Portal do Professor. Edição 109 - Prêmio Vivaleitura - 7ª Edição. Acesso em junho, 2019.

\section{http://portaldoprofessor.mec.gov.br/noticias.html?idEdicao=124\&idCategoria=4}

TODA MATÉRIA https://www.todamateria.com.br/genero-dramatico/> acesso em dezembro de 2019 